\title{
EFEKTIVITAS TERA/TERA ULANG TIMBANGAN DALAM PERLINDUNGAN KONSUMEN DI KABUPATEN SEKADAU
}

\author{
${ }^{1}$ NATASYA APRILIANA, ${ }^{2}$ ERSA TRI FITRIASARI \\ ${ }^{1}$ UPTD Metrologi Legal Kabupaten Sekadau \\ ${ }^{2}$ Badan Pengembangan Sumberdaya Manusia Provinsi Kalimantan Barat \\ Email : ersa3.dhobithoh@gmail.com, apriliananatasya@gmail.com
}

\begin{abstract}
ABSTRAK
Pemerintah mempunyai akuntabilitas sebagai suatu keadaan dan kemampuan memberi jawaban terhadap perlindungan konsumen yaitu masyarakat luas dalam memaksimalkan peran dan fungsi etika, profesional standards sebagai pemberi pelayanan publik atau administrator publik. Jenis study penelitian ini adalah deskriptif menggunakan metode survei. Teknik pengumpulan data pada study penelitian deskriptif ini menggunakan teknik observasi dengan menggunakan instrumen penelitian lembar observasi checklist. Hasil study penelitian yaitu penilaian dari pre test didapatkan nilai rata - rata sebesar 49 dan setelah diberikan edukasi terkait pentingnya melakukan tera/tera ulang kemudian diberikan post test diperolehlah peningkatan nilai rata rata menjadi 93 dan dapat disimpulkan bahwa dengan hadirnya edukasi tentang pentingnya tera/tera ulang timbangan melalui infografis maka pelaku usaha merasa sangat terbantu dalam mengakses informasi terkait tera/tera ulang timbangan dan merasa puas serta menjadi lebih paham tentang pentingnya melakukan tera/tera ulang timbangan.
\end{abstract}

Kata kunci: Akses, Perlindungan dan Konsumen.

\section{ABSTRACT}

The government has accountability as a condition and the ability to provide answers to consumer protection, namely the wider community in maximizing the role and function of ethics, professional standards as public service providers or public administrators. This type of research study is descriptive using a survey method. The data collection technique in this descriptive research study uses observation techniques using a checklist observation sheet research instrument. The results of the research study, namely the assessment of the pre-test, obtained an average value of 49 and after being given education regarding the importance of doing calibration/re-calibration then given a post-test, it was obtained that the average value increased to 93 and it can be concluded that with the presence of education about the importance of calibration/calibration By re-calibrating the scales through infographics, business actors find it very helpful to access information related to calibrating/recalibrating the scales and feeling satisfied and becoming more aware of the importance of re-calibrating the scales.

Keywords: Access, Protection and Consumers.

\section{PENDAHULUAN}

Pengertian penilaian kinerja menurut Siagian (2004) merupakan pengukuran dan perbandingan hasil-hasil kinerja nyata dengan hasil-hasil yang diharapkan akan tercapai. Menurut Anthony dan Govindarajan (dikutip dari Sriani, 2004), sistem penilaian kinerja adalah suatu mekanisme yang memperbaiki kemungkinan untuk perusahaan agar strategi yang dijalankan dapat berhasil. Penilaian kinerja menurut Mulyadi dan Jony Setiawan (1999) yaitu penentuan secara periodik efektifitas operasional suatu organisasi, bagian organisasi dan pegawai berdasarkan sasaran, standar dan kriteria yang telah ditetapkan.

Efektivitas adalah ukuran berhasil tidaknya suatu organisasi mencapai tujuannya. Apabila suatu organisasi berhasil mencapai tujuan, maka organisasi tersebut dikatakan telah berjalan dengan efektif (Dwiyanto 2002;47). Efektivitas hanya melihat apakah suatu program atau kegiatan telah mencapai tujuan yang telah ditetapkan. Efisiensi merupakan hal penting dari tiga pokok bahasan value of money. Rasio efisiensi menggambarkan perbandingan antara 
besaran biaya yang dikeluarkan untuk memperoleh pendapatan dengan realisasi pendapatan yang diterima.

Tera menurut Undang-undang metrology Legal No. merupakan hal menandai dengan tanda tera sah atau tanda tera batal yang berlaku, atau memberikan keterangan-keterangan tertulis yang bertanda tera sah atau tanda tera batal yang berlaku dilakukan oleh pegawai berhak atau Penera untuk melakukannya berdasarkan pengujian yang dijalankan atas UTTP yang belum dipakai, sedangkan Tera Ulang adalah hal menandai berkala dengan tanda tera sah atau tanda tera batal yang berlaku, atau memberikan keterangan-keterangan tertulis yang bertanda tera sah atau tanda tera batal yang berlaku, dilakukan oleh pegawai-pegawai yang berhak melakukannya berdasarkan pengujian yang dijalankan atas UTTP yang telah ditera.

Peralatan yang dilakukan tera dan tera ulang adalah alat ukur, alat takar, alat timbang dan alat perlengkapnnya. Alat ukur ialah alat yang diperuntukkan atau dipakai bagi pengukuran kuantitas dan atau kualitas, Alat takar, adalah alat yang diperuntukkan atau dipakai bagi pengukuran kuantitas atau penakaran, Alat Timbang adalah alat yang diperuntukkan atau dipakai bagi pengukuran massa atau penimbangan dan Alat perlengkapan ialah alat yang diperuntukkan atau dipakai sebagai pelengkap atau tambahan pada alat-alat ukur, takar, atau timbang, yang menentukan hasil pengukuran, penakaran atau penimbangan (Undang-undang Metrologi legal No. 2,1981).

Surat edaran Direktur Jenderal Standarisasi dan Perlindungan Konsumen Nomor 01/SPK/SE/5/2011 tentang Tera UTTP mengamanatkan agar Alat-Alat Ukur, Takar, Timbang, dan Perlengkapannya, yang selanjutnya disebut UTTP yang secara langsung atau tidak langsung digunakan atau disimpan dalam keadaan siap pakai untuk keperluan menentukan hasil pengukuran, penakaran, atau penimbangan wajib ditera atau ditera ulang. Kebijakan - kebijakan yang dikeluarkan tersebut merupakan sebagian regulasi turunan dari Undang- Undang No. 2 Tahun 1981 tentang Metrologi Legal. Di Kabupaten Sekadau sendiri Alat Ukur Takar Timbang dan Perlengkapannya (UTTP) yang terdata sudah melakukan Tera/Tera Ulang Timbangan sebanyak 499 buah timbangan dari target 746 buah timbangan. Hal ini menunjukkan bahwa tingkat kesadaran pelaku usaha tentang pentingnya melakukan Tera/Tera Ulang Timbangan belum maksimal dikarenakan masih minimnya informasi yang dapat diakses.

Dalam Pasal 1 huruf q dan r Undang-Undang Nomor 2 Tahun 1981 tentang Metrologi Legal menjelaskan pengertian dari tera dan tera ulang, dimana tera adalah hal menandai dengan tanda tera sah atau tanda tera batal yang berlaku, atau memberikan keterangan- keterangan tertulis yang bertanda tera sah atau tanda tera batal yang berlaku, dilakukan oleh pegawaipegawai yang berhak melakukanya berdasarkan pengujian yang dijalankan atas alat - alat ukur, takar, timbang, dan perlengkapanya yang belum dipakai. Sedangkan tera ulang ialah hal menandai berkala dengan tanda-tanda tera sah atau tera batal yang berlaku atau memberikan keterangan-keterangan tertulis yang bertanda tera sah atau tera batal yang berlaku, dilakukan oleh pegawai - pegawai yang berhak.

Berdasarkan latar belakang diatas, maka ditemukanlah suatu rumusan masalah yang kerap kali ditemukan yaitu "Mengapa pelaku usaha kurang memahami pentingnya tera/tera ulang timbangan?". Pentingnya edukasi pemahaman pelaku usaha tentang pentingnya tera ulang timbangan dengan media infografis di lingkungan pasar Kabupaten Sekadau sehingga pelaku usaha dapat memahami mengenai pentingnya tera/tera ulang timbangan dapat mengakses informasi mengenai tera/tera ulang timbangan dengan mudah sehingga terciptanya pasar tertib ukur dalam transaksi perdagangan guna melindungi kepentingan konsumen dan produsen

\section{METODE PENELITIAN}

Penelitian ini menggunakan pendekatan penelitian kualitatif, Menurut Boghdan \& Biklen (1875), penelitian kualitatif adalah salah satu prosedur yang menghasilkan data deskriptif berupa ucapan atau tulisan dan sikap orang-orang yang diamati. Perlindungan 
konsumen urgent untuk dilaksanakan tentang pentingnya tera timbangan dalam perlindungan konsumen di lingkungan pasar Kabupaten Sekadau dengan target 30 orang pelaku usaha.

\section{HASIL DAN PEMBAHASAN}

Edukasi kepada pelaku usaha kegiatan yang telah dilakukan eksekusi kegiatan berupa mengunggah video edukasi kedalam akun resmi media sosial milik UPTD Metrologi Legal Kabupaten Sekadau serta melakukan penempelan infografis ke beberapa lokasi di pasar oleh metrologi yang bertugas, sekaligus memberikan pemaparan singkat kepada pelaku usaha tentang pentingnya melakukan tera ulang timbangan kemudian pre test dan post test kepada pelaku usaha untuk mengetahui gambaran tentang pemahaman pelaku usaha setelah diberikan edukasi singkat.

Jaminan kebenaran pengukuran perlu ada karena pengukuran sendiri menjadi hal yang tidak terpisahkan dalam kehidupan sehari - hari masyarakat sebagai contoh dalam transaksi perdagangan, dunia kesehatan dan lain-lain sehingga bila tidak terjamin kebenaran pengukuran akan sangat merugikan masyarakat atau konsumen. Penera merupakan jabatan yang ada di UPTD Metrologi Legal yang salah satu tugasnya menjamin kebenaran pengukuran khususnya dengan melakukan kegiatan tera dan tera ulang UTTP. Menera ialah hal menandai dengan tanda tera sah atau tera batal yang berlaku dilakukan oleh pegawai berhak (UU No.2 Tahun 1981 tentang Metrologi Legal).

Implementasi kegiatan aktualisasi yang dilaksanakan di Unit Pelaksana Teknis Daerah Metrologi Legal (UPTDML) Kabupaten Sekadau ditemukan permasalahan yaitu kurangnya pemahaman pelaku usaha tentang pentingnya tera/tera Ulang timbangan. Untuk lebih jelasnya dapat dilihat pada table 4.1 dibawah ini. Berdasarkan pemetaan yaitu terbatasnya informasi yang diperoleh pelaku usaha mengenai pentingnya tera/tera ulang timbangan melihat data potensi UTTP yang tidak memenuhi target tahunannya dikarenakan kurangnya pemahaman pelaku usaha tentang pentingnya tera/tera ulang yang disebabkan oleh karena terbatasnya informasi yang diperoleh pelaku usaha. Jika dilihat, target pertahunnya UTTP yang bertanda tera sah seharusnya 746 buah, tetapi hingga saat ini tercatat hanya 499 buah UTTP yang sudah melakukan tera/tera ulang.

Pertimbangan dari aspek untuk tercapainya pasar tertib ukur, pemerintah sudah mengeluarkan kebijakan-kebijakan yang dinyatakan dalam Peraturan Menteri Perdagangan No. 08/M- DAG/PER/3/2010 tentang Alat-Alat Ukur, Takar, Timbang, dan Perlengkapannya (UTTP) yang wajib ditera dan ditera ulang, dan surat edaran Direktur Jenderal Standarisasi dan Perlindungan Konsumen Nomor 01/SPK/SE/5/2011 tentang Tera UTTP mengamanatkan agar Alat - Alat Ukur, Takar, Timbang, dan perlengkapannya, yang selanjutnya disebut UTTP yang secara langsung atau tidak langsung digunakan atau disimpan dalam keadaan siap pakai untuk keperluan menentukan hasil pengukuran, penakaran, atau penimbangan wajib ditera atau ditera ulang.

Menimbulkan dampak yang merugikan bagi pembeli maupun pelaku usaha itu sendiri karena jaminan kebenaran pengukuran tidak bisa dipastikan jika pelaku usaha tidak menyadari pentingnya melakukan tera/tera ulang timbangan yang digunakan dalam bertransaksi, yang tentunya juga berdampak bagi UPTD Metrologi Legal Kabupaten Sekadau, yaitu belum sepenuhnya berhasil menciptakan pasar tertib ukur sesuai visi dan misi organisasi.

Evaluasi melalui hasil pre test dan post test terkait pemahaman pelaku usaha tentang pentingnya tera/tera ulang timbangan melalui media infografis di lingkungan pasar Kabupaten Sekadau. Menempelkan infografis ke beberapa lokasi di pasar, sekaligus memberikan edukasi singkat kepada pelaku usaha tentang pentingnya melakukan tera ulang timbangan kemudian membagikan pre test kemudian post test kepada pelaku usaha serta mengunggah video edukasi kedalam akun resmi media sosial milik UPTD Metrologi Legal Kabupaten Sekadau.

UPTD Metrologi Legal Kabupaten Sekadau melakukan kegiatan tera/tera ulang demi terwujudnya tertib ukur di Kabupaten Sekadau. Di masa pandemi ini pelaksanaan aktualisasi 
tetap menerapkan protokol kesehatan. Salah satu kegiatan yang dilakukan adalah memberikan edukasi kepada pelaku usaha terkait pentingnya melakukan tera/tera ulang timbangan. Infografis ke beberapa lokasi di pasar sekaligus memberikan edukasi singkat kepada pelaku usaha tentang pentingnya melakukan tera ulang timbangan kemudian membagikan pre test dan post test kepada pelaku usaha serta mengunggah video edukasi kedalam akun resmi media sosial milik UPTD Metrologi Legal Kabupaten Sekadau, dilakukan dengan kerjasama yang baik serta kompak dan harus dilakukan secara terarah agar informasi tersampaikan dengan baik kepada pelaku usaha tentunya jadi lebih mudah memperoleh informasi sehingga untuk memahami pentingnya melakukan tera/tera ulang menjadi lebih mudah.

Kegiatan edukasi pemahaman pelaku usaha tentang pentingnya tera/tera ulang timbangan di lingkungan pasar Kabupaten Sekadau bertempat di wilayah Pasar Sekadau melakukan penempelan media infografis di beberapa titik lokasi dipasar, kemudian memberikan edukasi singkat kepada pelaku usaha di Pasar skaligus membagikan pre test kemudian post test kepada 30 orang pelaku usaha. Dengan jumlah soal yang sama yaitu masing - masing 6 soal dan mempunyai nilai minimal 10 point dan maksimal 100 point.

Edukasi terkait pentingnya tera/tera ulang timbangan bagi pelaku usaha dengan harapan memudahkan pelaku usaha dalam mengakses informasi mengenai tera/tera ulang timbangan sehingga pelaku usaha dapat memahami betul mengenai pentingnya tera/tera ulang timbangan agar terciptanya pasar tertib ukur dalam transaksi perdagangan guna melindungi kepentingan konsumen dan produsen di Kabupaten Sekadau.

Berdasarkan hasil evaluasi dari penilaian dari pre test didapatkan nilai rata - rata sebesar 49 dan setelah diberikan edukasi terkait pentingnya melakukan tera/tera ulang kemudian diberikan post test diperolehlah peningkatan nilai rata - rata menjadi 93 dan dapat disimpulkan bahwa dengan hadirnya edukasi tentang pentingnya tera/tera ulang timbangan melalui infografis maka pelaku usaha merasa sangat terbantu dalam mengakses informasi terkait tera/tera ulang timbangan dan merasa puas serta menjadi lebih paham tentang pentingnya melakukan tera/tera ulang timbangan.

Kegiatan Pentingnya Tera/Tera Ulang Timbangan Di Lingkungan Pasar Kabupaten Sekadau bertempat di wilayah Pasar Sekadau. Petugas melakukan penempelan media infografis di beberapa titik lokasi dipasar, kemudian memberikan edukasi singkat kepada pelaku usaha di Pasar skaligus membagikan pre test kemudian post test kepada 30 orang pelaku usaha. Dengan jumlah soal yang sama yaitu masing - masing 6 soal dan mempunyai nilai minimal 10 point dan maksimal 100 point.

Berdasarkan kegiatan tersebut petugas melakukan penilaian dari hasil jawaban yang didapat sebagai berikut :

Tabel 1. Penilaian hasil jawaban

\begin{tabular}{|c|c|l|}
\hline NILAI & PRE TEST & \multicolumn{1}{|c|}{$\begin{array}{c}\text { POST } \\
\text { TEST }\end{array}$} \\
\hline 10 & 0 Jawaban & 0 Jawaban \\
\hline 20 & 4 Jawaban & 0 Jawaban \\
\hline 30 & 2 Jawaban & 0 Jawaban \\
\hline 40 & 7 Jawaban & 0 Jawaban \\
\hline 50 & 7 Jawaban & 0 Jawaban \\
\hline 60 & 4 Jawaban & 0 Jawaban \\
\hline 70 & 2 Jawaban & 1 Jawaban \\
\hline 80 & 4 Jawaban & 5 Jawaban \\
\hline
\end{tabular}


Vol 2. No. 1, Januari 2022 P-ISSN : 2774-8030, e-ISSN : 2774-8030

\begin{tabular}{|l|c|c|}
\hline \multicolumn{1}{|c|}{90} & 0 Jawaban & 9 Jawaban \\
\hline \multicolumn{1}{|c|}{100} & 0 Jawaban & 15 Jawaban \\
\hline $\begin{array}{l}\text { JUMLA } \\
\text { H NILAI }\end{array}$ & 1.470 & 2.780 \\
\hline $\begin{array}{l}\text { NILAI } \\
\text { RATA - } \\
\text { RATA }\end{array}$ & 49 & 93 \\
\hline
\end{tabular}

Berdasarkan hasil evaluasi berdasarkan penilaian dari pre test didapatkan nilai rata rata sebesar 49 dan setelah diberikan edukasi terkait pentingnya melakukan tera/tera ulang kemudian diberikan post test diperolehlah peningkatan nilai rata - rata menjadi 93 dan dapat disimpulkan bahwa dengan hadirnya edukasi tentang pentingnya tera/tera ulang timbangan melalui infografis maka pelaku usaha merasa sangat terbantu dalam mengakses informasi terkait tera/tera ulang timbangan dan merasa puas serta menjadi lebih paham tentang pentingnya melakukan tera/tera ulang timbangan.

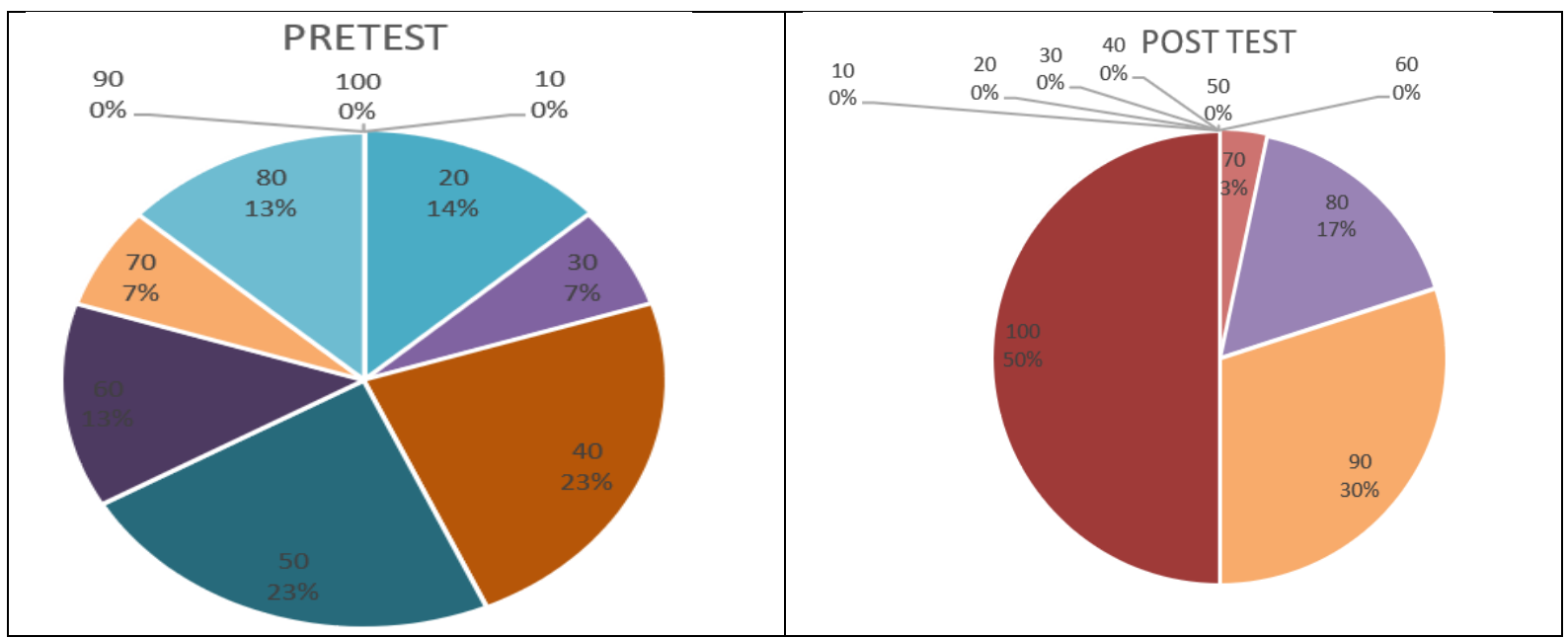

Gambar 1. Grafik perbadingan hasil pretest dan post test

Berdasarkan hasil evaluasi berdasarkan penilaian dari pre test didapatkan nilai rata rata sebesar 49 dan setelah diberikan edukasi terkait pentingnya melakukan tera/tera ulang kemudian diberikan post test diperolehlah peningkatan nilai rata - rata menjadi 93 dan dapat disimpulkan bahwa dengan hadirnya edukasi tentang pentingnya tera/tera ulang timbangan melalui infografis maka pelaku usaha merasa sangat terbantu dalam mengakses informasi terkait tera/tera ulang timbangan dan merasa puas serta menjadi lebih paham tentang pentingnya melakukan tera/tera ulang timbangan.

\section{KESIMPULAN}

Bagi UPTD Metrologi Legal Sekadau diharapkan dapat mendukung peserta dalam merealisasikan inovasi yang telah dihasilkan dari pelatihan dasar berupa Edukasi tentang pentingnya tera/tera ulang timbangan melalui infografis. Selain itu, diharapkan kegiatan ini bisa menjadi program yang berkelanjutan

Dibuat media infografis sebagai media edukasi menarik dan lebih variatif dari waktu ke waktu guna mendukung terpenuhinya kebutuhan informasi bagi pelaku usaha. Media infografis tentang edukasi singkat tentang pentingnya tera/tera ulangtimbangan dan Menyusunsoal pre test dan post testyang dibagikan kepada pelaku usaha 


\section{DAFTAR PUSTAKA}

Denhardt, Kathryn G. 1988. The ethics of Public Service. Westport, Connecticut : Greenwood Press.

Dough Lennick \& Fred Kiel, Phd. 2005. Moral Intelegence. New York: Wharton School Publishing.

Dwiyanto,A. 2002. Reformasi birokrasi publik Indonesia.Yogyakarta : UGM

Hara, AE. 2000. Kebanggaan Berbangsa Indonesia. Kompas.

Mowday, R.T., Porter, L.W \& Streers, R.M (1982). Employee Organization Linkages: The Psychology Of Commitment, Absenteeism, and Turnover. New York.

Peraturan Bupati Sekadau Nomor 59 Tahun 2018 Tentang Pembentukan, Susunan Organisasi, Tugas dan Fungsi, Serta Tata Kerja Unit Pelaksana Teknis Daerah Metrologi Legal Kabupaten Sekadau.

Rasul,Syahrudin, 2003. Pengintegrasian Sistem Akuntabilitas Kinerja dan Anggaran dalam Perspektif UU No.17/2003 Tentang Keuangan Jegara. Jakarta : PNRI.

Siagian, sondang. 2004. Manajemen Strategik. Bumi Aksara : Jakarta.

Sriani, Ni Ketut. 2004. Kinerja KPP Denpasar dan Pemungutan Pajak Penghasilan. Tesis. Magister Ekonomi Pembangunan pada Program Pasca Sarjana Universitas Udayana, Denpasar.

Surat Edaran Direktur Jenderal Standardisasi dan Perlindungan Konsumen Nomor 01/SPK/SE/5/2011 Tentang Tera Alat-Alat Ukur, Takar, Timbang, dan Perlengkapannya (UTTP).

Turner, Mark, Hulme, And David, 1997.Governance. Administrasi, and Development: Making The State Work. London: MacMillan Press Ltd.

Undang - Undang Republik Indonesia Nomor 2 Tahun 1981 Tentang Metrologi Legal 